\title{
BMJ Open Client-perpetrated gender-based violence among female sex workers in conflict-affected Northern Uganda: a cross-sectional study
}

\author{
Simple Ouma (D) , ${ }^{1,2}$ Rawlance Ndejjo (D) , ${ }^{3}$ Catherine Abbo, ${ }^{4}$ \\ Nazarius M Tumwesigye ${ }^{2}$
}

To cite: Ouma S, Ndejjo R, Abbo C, et al. Client-perpetrated gender-based violence among female sex workers in conflictaffected Northern Uganda: a cross-sectional study. BMJ Open 2021;11:e046894. doi:10.1136/ bmjopen-2020-046894

- Prepublication history for this paper is available online To view these files, please visit the journal online (http://dx.doi org/10.1136/bmjopen-2020046894).

Received 14 November 2020 Accepted 01 September 2021

Check for updates

(c) Author(s) (or their employer(s)) 2021. Re-use permitted under CC BY-NC. No commercial re-use. See rights and permissions. Published by BMJ.

${ }^{1}$ Research Department, The AIDS Support Organization, Kampala, Uganda

${ }^{2}$ Department of Epidemiology and Biostatistics, School of Public Health, College of Health Sciences, Makerere University, Kampala, Uganda

${ }^{3}$ Department of Disease Control and Environmental Health, School of Public Health, College of Health Sciences, Makerere University, Kampala, Uganda ${ }^{4}$ Department of Psychiatry, School of Medicine, College of Health Sciences, Makerere University, Kampala, Uganda

Correspondence to

Dr Simple Ouma;

oumasimple@gmail.com

\section{ABSTRACT}

Study objective To determine the prevalence and associated factors of client-perpetrated gender-based violence among female sex workers in conflict-affected Northern Uganda.

Design and settings We conducted a cross-sectional study among female sex workers in Gulu district in conflict-affected Northern Uganda.

Participants The study participants included 300 female sex workers aged $18+$ years. The participants were selected using simple random sampling from a database of female sex workers maintained at a national nongovernmental organisation in Gulu.

Outcome measure The outcome measure was selfreported exposure to client-perpetrated gender-based violence.

Methods We used a pretested semistructured questionnaire to collect data on sociodemographic characteristics, sex work-related characteristics, alcohol use, illicit drug use, HIV status and self-reported exposure to client-perpetrated gender-based violence. Then, data were entered into Epi Info V.7 and analysed using Stata V.14.0.

Results Among participants, $61.0 \%$ reported clientperpetrated gender-based violence. Economic (58.7\%) and emotional (52.0\%) violence were the most common forms of client-perpetrated gender-based violence in this population. Independently, being: street-based (adjusted OR=9.66, 95\% Cl 2.78 to 33.5), mobile (adjusted $\mathrm{OR}=3.21,95 \% \mathrm{Cl} 1.83$ to 5.64 ), HIV-positive (adjusted $\mathrm{OR}=1.90,95 \% \mathrm{Cl} 1.09$ to 3.31 ) and a low-income earner (<USh200 000 monthly) (adjusted OR=2.26, 95\% Cl 1.18 to 4.30 ) were positively associated with exposure to clientperpetrated gender-based violence.

Conclusions There is a high prevalence of clientperpetrated gender-based violence among female sex workers in conflict-affected Northern Uganda. Furthermore, female sex workers who were street-based, mobile, HIV-positive and low-income earners were more likely to experience client-perpetrated gender-based violence. The ministry of health and the development partners need to provide targeted public health interventions to prevent and manage the rampant gender-based violence among this underserved population.
Strengths and limitations of this study

- This work is among the first studies on clientperpetrated gender-based violence among female sex workers in conflict-affected settings.

- Likewise, the study samples were representative and generalisable since they were selected using a probability sampling technique.

- However, we asked female sex workers about their past exposures to client-perpetrated gender-based violence and could have resulted in recall or information biases.

\section{INTRODUCTION}

Gender-based violence (GBV) refers to harmful acts directed at individuals based on their gender. ${ }^{1}$ Examples of GBV include sexual, physical, mental and economic harm inflicted in public or private and the threats of violence, coercion and manipulation. ${ }^{1} \mathrm{GBV}$ is a violation of human rights that can be lifethreatening ${ }^{1}$ and thus need close attention, especially among vulnerable populations like female sex workers (FSWs). Although hostility from the more than 20 years of the Lord's Resistant Army (LRA) war in Northern Uganda has ceased, the region has not achieved complete reconciliation, societal integration and economic recovery. ${ }^{2}$ In addition, the LRA conflict has led to increased vulnerability to HIV infection, ${ }^{3} \mathrm{GBV}^{4}$ and depression ${ }^{5}$ in Northern Uganda.

GBV is rooted in gender inequality, abuse of power and harmful norms that leave survivors unable to achieve legal, social, political and economic equality in society. ${ }^{6}$ Vulnerable groups like FSWs are at increased risk of exposure to $\mathrm{GBV}^{7}$ because of the rampant alcohol use and illicit drug use among FSWs, ${ }^{8}$ which increases their odds of GBV. ${ }^{9}$ In addition, there is a high level of intimate partner violence among FSWs in Northern Uganda, 
which in turn may lead to client-perpetrated GBV. ${ }^{10}$ Furthermore, FSWs in Gulu are highly mobile ${ }^{8}$ and thus at a greater risk of client-perpetrated GBV. ${ }^{11}{ }^{12}$ Moreover, the illegality of sex work in Uganda ${ }^{13}$ makes it difficult for FSWs to prevent or seek management for GBV through social support networks, access to social services or access to legal or GBV services. ${ }^{14} 15$

If left untreated, GBV can lead to poverty, alcohol abuse, inconsistent condom use, ${ }^{16}{ }^{17}$ reduction in condom self-efficacy, ${ }^{18}$ poor sexual and reproductive health ${ }^{19}$ and mental disorders. ${ }^{20-23}$ Thus, there is an urgent need to screen, prevent and manage GBV among FSWs in conflictaffected Northern Uganda. This requires an in-depth understanding of the epidemiology of GBV among FSWs to guide the development of context-specific GBV interventions by the ministry of health and development partners. Therefore, we conducted this study to determine the prevalence and associated factors of client-perpetrated GBV among FSWs in conflict-affected Northern Uganda.

\section{METHODS}

\section{Study setting, design and population}

We conducted a cross-sectional study among FSWs operating in Gulu district in Northern Uganda. In Uganda, the highest burden of HIV infections is among the FSWs. ${ }^{24}$ Northern Uganda remains negatively impacted by the LRA conflict since many people have not fully recovered from the more than 20 years of war that devastated social and economic livelihoods. Currently, more than $80 \%$ of the inhabitants of Gulu practice subsistence farming. ${ }^{25}$ Of estimated 1425 FSWs who operate in the district ${ }^{26}$ the majority live and work in Gulu municipality. Almost all FSWs in the region get HIV treatment, care or prevention services from The AIDS Support Organization (TASO). TASO is a national non-governmental organisation $(\mathrm{NGO})^{27}$ highly specialised in HIV services provision in Uganda. In Gulu, TASO Gulu clinic had mapped all (1300+) FSWs who operate in the district. The updated FSWs' database contains sex work venues, hang-out places, mobile phone contacts and residence. This study was limited to only the FSWs who were operating in Gulu and aged 18+ years. We excluded FSWs who were less than 18 years of age due to the ethical dilemma of obtaining parental consent among adolescent FSWs who do sex work without parental knowledge yet live with their parents or guardians.

\section{Sample size and sampling}

A sample size of 380 participants was determined using Cochran $(1963,1975)^{28}$ formula as part of a project that studied depression among FSWs in Gulu and presented elsewhere. ${ }^{8}$ We identified 789 eligible FSWs from the database then used a simple random sampling to select 380 potential participants using an online random number generator. To minimised non-response bias, we reached out to FSWs by telephone or their peers to schedule appointments, physically traced them using existing mapping information or met them during their clinic days. We successfully tracked and contacted 302 out of 380 selected FSWs, of whom 300 were consented and interviewed within the conducive places of their choice.

\section{Data collection}

We collected data between March and June 2020. Using a pretested semistructured questionnaire developed in English and translated into Acholi language, we conducted face-to-face interviews to collect information from each participant. Before data collection, we pretested the study tools among 20 FSWs in the neighbouring Amuru district to check for consistency in question interpretation and language appropriateness. Then, the first author and a trained female research assistant collected data in either Acholi or English depending on the participant's literacy level and language preference. Independent variables included sociodemographic characteristics (like age, education, religion and marital status), sex work-related characteristics (like duration of sex work, average monthly income, place of sex work and mobility), alcohol and illicit drug use, and HIV status. We determined intraregional sex work-related mobility by asking study participants about localities where they provided sexual services. We considered FSWs operating both in rural and urban localities to be mobile since they move long distances to do sex work. The outcome variable for this study was client-perpetrated GBV. We adopted the study questionnaire for assessing client-perpetrated GBV from previous research conducted among FSWs in Kampala, Uganda. ${ }^{29}$ We asked each participant whether her client(s) ever: refused to compensate her for sexual services (economic violence), verbally abused (insulted) her (emotional violence), physically abused/beat her (physical violence) or forced her to have sex/raped her (sexual violence). Reporting either economic, emotional, physical or sexual violence by male clients was considered client-perpetrated GBV.

\section{Data management and statistical analysis}

Data were entered and cleaned in Epi Info V.7 then exported to Stata V.14.0 for analysis. Univariate results were described using either frequency with corresponding proportions or mean with corresponding SDs as appropriate. We ran bivariable logistic regression analyses to examine the relationships between clientperpetrated GBV and various independent factors. We reported bivariable results using unadjusted ORs (uORs) with corresponding CIs and $\mathrm{p}$ values. Then, we considered all independent variables with $\mathrm{p}<0.20$ for inclusion in multivariable logistic regression. ${ }^{30}$ Controlling for age, marital status and monthly income, we entered all eligible independent variables into a multivariable logistic regression model at the beginning stage of model building. We used the backward elimination method and sequentially removed each factor with the least significant $p$ value while testing model fit using the goodness-of-fit test until we obtained the best fit model. We described results from 
the multivariable logistic regression model using adjusted ORs (aORs) with corresponding 95\% CIs and $p$ values. After fitting the multivariable logistic regression model, we conducted sensitivity and specificity analyses to estimate the model's predictive power and linktest to check for specification error.

\section{Participant and public involvement}

We involved study participants and the public in the dissemination of study findings. We shared study findings with relevant local authorities in Gulu and NGOs that provide healthcare services to FSWs in the region. The complex nature of sex work made it difficult to actively involve participants or the public in study design, study conduct or reporting plans. However, the first author has been working among FSWs for more than 3 years. This personal experience and interactions with FSWs informed study design and conduct. Additionally, peers of FSWs were involved in the identification and tracking of participants.

\section{RESULTS}

\section{Sociodemographic and sex work-related characteristics of study participants}

We randomly sampled 380 eligible FSWs for this study. However, we successfully traced only $302(79.5 \%)$ participants and contacted them to participate, of whom 300 were consented and enrolled with a response rate of $99.3 \%$. The participants' mean age was 26.4 years $(\mathrm{SD} \pm 6$, range $=18-50$ years), of whom $40 \%$ were below 25 years old. Additionally, $62.0 \%$ of the participants had no or primary education, $51.3 \%$ migrated to Gulu, only $14.3 \%$ were married/cohabiting and $60.7 \%$ were Catholics. Among the participants, $39.7 \%$ had been FSWs for 3-5 years, $63.9 \%$ earned money mainly through sex work and $43.5 \%$ had low monthly income/earned below the median monthly income of FSWs (USh200000 [US\$60]) (table 1).

\section{Prevalence of client-perpetrated GBV among FSWs in Gulu district}

During sex work, $61.0 \%$ of the participants experienced at least one incidence of client-perpetrated GBV. The most common forms of GBV were economic (58.7\%) and emotional $(52.0 \%)$ violence, while the least common form of GBV was sexual violence $(21.0 \%)$. Further analysis showed that $32.7 \%$ of the participants reported two or three different forms of client-perpetrated GBV. Lastly, about one-fifth $(19.0 \%)$ of the participants experienced all the four forms of client-perpetrated GBV (table 2).

\section{Predictors of client-perpetrated GBV among FSWs}

At bivariate level, participants who experienced clientperpetrated GBV were more likely to be based in the street $(\mathrm{uOR}=12.0,95 \%$ CI 3.64 to $39.8, \mathrm{p}<0.001)$, the club (uOR=3.16, 95\% CI 1.66 to $6.00, \mathrm{p}<0.001)$, brothel (uOR=2.91, 95\% CI 1.80 to $4.70, \mathrm{p}<0.001)$, bar (uOR:
Table 1 Sociodemographic and sex work-related characteristics of study participants

\begin{tabular}{|c|c|c|}
\hline Characteristic & No $(\mathrm{N}=300)$ & $\%$ \\
\hline \multicolumn{3}{|c|}{ Age (completed years) } \\
\hline$<25$ & 120 & 40.0 \\
\hline $25-29$ & 85 & 28.3 \\
\hline $30+$ & 95 & 31.7 \\
\hline \multicolumn{3}{|l|}{ Education } \\
\hline$\leq$ Primary level & 186 & 62.0 \\
\hline$\geq$ Secondary level & 114 & 38.0 \\
\hline \multicolumn{3}{|l|}{ District of origin } \\
\hline Gulu & 146 & 48.7 \\
\hline Others & 154 & 51.3 \\
\hline \multicolumn{3}{|l|}{ Married/cohabiting ${ }^{*}$} \\
\hline No & 257 & 85.7 \\
\hline Yes & 43 & 14.3 \\
\hline
\end{tabular}

Religion

\begin{tabular}{|c|c|c|}
\hline None/others & 36 & 12.0 \\
\hline Catholic & 182 & 60.7 \\
\hline Protestant & 48 & 16.0 \\
\hline Born again & 34 & 11.3 \\
\hline \multicolumn{3}{|l|}{ Years of sex work } \\
\hline$\leq 2$ & 108 & 36.0 \\
\hline $3-5$ & 119 & 39.7 \\
\hline$>5$ & 73 & 24.3 \\
\hline \multicolumn{3}{|c|}{ Sex work is the only income source } \\
\hline No & 108 & 36.1 \\
\hline Yes & 191 & 63.9 \\
\hline \multicolumn{3}{|l|}{ Monthly income (USh)* } \\
\hline$\geq$ USh300000 & 114 & 38.1 \\
\hline USh200 000 to $<$ USh300000 & 55 & 18.4 \\
\hline$<$ USh200000 & 130 & 43.5 \\
\hline \multicolumn{3}{|l|}{ Practice mobile sex work } \\
\hline No & 161 & 53.7 \\
\hline Yes & 139 & 46.3 \\
\hline \multicolumn{3}{|l|}{ Use illicit drug } \\
\hline No & 216 & 72.0 \\
\hline Yes & 84 & 28.0 \\
\hline \multicolumn{3}{|c|}{ Took alcohol during interview week ${ }^{*}$} \\
\hline No & 107 & 36.3 \\
\hline Yes & 188 & 63.7 \\
\hline \multicolumn{3}{|c|}{ Frequency of alcohol consumption } \\
\hline Never & 79 & 26.5 \\
\hline Sometimes & 52 & 17.5 \\
\hline Daily & 167 & 56.0 \\
\hline \multicolumn{3}{|l|}{ Reported HIV status* } \\
\hline Negative & 173 & 57.9 \\
\hline Positive & 126 & 42.1 \\
\hline
\end{tabular}

Continued 
Table 1 Continued

\section{Characteristic}

No $(\mathrm{N}=300)$

$\%$

*Missing data: marital status (2), alcohol consumption (2), income (1) and HIV status (1).

USh, Uganda Shilling

2.16, $95 \%$ CI 1.29 to $3.60, \mathrm{p}=0.003)$ or mobile $(\mathrm{uOR}=3.99$, 95\% CI: 2.41 to $6.62, \mathrm{p}<0.001)$. In addition, illicit drug use $(\mathrm{uOR}=2.21,95 \% \mathrm{CI} 1.27$ to $3.86, \mathrm{p}=0.005)$, age ( $\mathrm{uOR}=2.05,95 \%$ CI 1.14 to $3.68, \mathrm{p}=0.016$ ) and living with HIV (uOR: $1.72,95 \%$ CI 1.07 to $2.79, \mathrm{p}=0.026$ ) were all positively associated with client-perpetrated GBV. After controlling for age, marital status and monthly income, multivariable logistic regression results showed that: street-based sex work (aOR=9.66, 95\% CI 2.78 to 33.5), mobility (aOR=3.21, 95\% CI 1.83 to 5.64), living with HIV $(\mathrm{aOR}=1.90,95 \% \mathrm{CI} 1.09$ to 3.31$)$ and low monthly income $(\mathrm{aOR}=2.26,95 \%$ CI 1.18 to 4.30$)$ all remained positively associated with client-perpetrated GBV. Regression diagnostic tests showed that the adjusted model had; good predictive power (0.77), non-significant goodness-of-fit test outcome $(\mathrm{p}=0.97)$ and no specification error (linktest hatsq, $\mathrm{p}=0.38$ ) (table 3).

\section{DISCUSSION}

There is a high prevalence of client-perpetrated GBV $(61.0 \%)$ among FSWs in conflict-affected Northern Uganda. It is worth noting that there is a gap in the literature on client-perpetrated GBV among FSWs in conflict-affected settings. Moreover, the current magnitude of client-perpetrated GBV among FSWs in Gulu is much lower than in Kampala $(82 \%){ }^{29}$ This could be because, in our study, a much smaller proportion of FSWs solely depended on sex work for income $(63.9 \%)$ than in Kampala (95\%). In light of a close relationship between HIV infection and GBV, ${ }^{31}$ the ministry of health and healthcare managers need to develop robust GBV

Table 2 Prevalence and forms of client-perpetrated GBV among study participants

\begin{tabular}{|c|c|c|}
\hline Characteristics & No $(\mathrm{N}=300)$ & $\%$ \\
\hline \multicolumn{3}{|l|}{ Experienced client-perpetrated GBV } \\
\hline No & 117 & 39.0 \\
\hline Yes & 183 & 61.0 \\
\hline \multicolumn{3}{|l|}{ Client-perpetrated GBV experienced } \\
\hline Economic violence & 176 & 58.7 \\
\hline Emotional violence & 156 & 52.0 \\
\hline Physically violence & 145 & 48.3 \\
\hline Sexual violence & 63 & 21.0 \\
\hline Two or three forms of violence & 98 & 32.7 \\
\hline All forms of violence & 57 & 19.0 \\
\hline
\end{tabular}

GBV, gender-based violence. interventions to address the GBV situation among FSWs in Uganda. There is also a need to navigate the legal challenge of criminalising sex work in the country. ${ }^{13}$ Otherwise, the illegality of sex work will continue to perpetuate violence against FSWs and affect their ability to seek medical support, form support networks or take legal action against the perpetrators. The ministry of health and health managers should equip and support FSWs to deal with GBV.

Several factors were found to increase the odds of client-perpetrated GBV among FSWs. Importantly, street-based FSWs were ten times more likely to experience client-perpetrated GBV than FSWs who conduct sex work elsewhere. Available studies are in agreement with current findings. ${ }^{32-34}$ Therefore, targeted measures are urgently needed to protect FSWs who operate on the street. These measures could include: provision of information and safety tips, creating awareness about legal and civil rights of FSWs, training street-based FSWs in self-defence, forming self-defence groups, providing defensive items like alarms and deterrent sprays, or developing warning systems for FSWs to inform their peers of potentially violent clients. ${ }^{35}$ It is high time NGOs and civil society organisations advocate for safe places for FSWs. There is also a need for more participatory research on how to make streets safer for FSWs. In addition, mobile FSWs were three times more likely to report clientperpetrated GBV than their non-mobile counterparts. This finding agrees with available reports among FSWs in India, Tanzania and Canada. ${ }^{11} 1236$ Mobile FSWs have less control over their work environment, yet male clients often refuse to use condoms with new FSWs. ${ }^{36}$ Therefore, mobile FSWs require special attention, especially in the fight against HIV. Likewise, HIV-positive FSWs had an increased odd of experiencing client-perpetrated GBV. This finding agrees with previous studies among people living with HIV ${ }^{37}$ and FSWs. ${ }^{738}$ Research has shown that this is a bidirectional relationship. ${ }^{39}{ }^{40}$ FSWs who suffer from GBV are at greater risk of HIV transmission due to inconsistent condom use. ${ }^{1617}$ Thus, the ministry of health and healthcare managers need to integrate GBV interventions within the existing HIV programmes to reduce HIV infections driven by the high prevalence of HIV $(33 \%)$ among FSWs. ${ }^{41}$ Lastly, FSWs with low income were twice more likely to experience client-perpetrated GBV. Only a few studies examined the relationship between client-perpetrated GBV and income. In Tanzania, income level did not affect client-perpetrated GBV. ${ }^{12}$ However, the current finding agrees with a study among FSWs in Ethiopia. ${ }^{42}$ Low-income earning FSWs may engage in riskier sexual behaviours, have poor negotiation for safer sex with clients, or operate in unsafe places like the street. Thus, there is a need for economic empowerment to provide FSWs with alternative sources of income or improve their welfare. 
Table 3 Factors associated with client-perpetrated GBV among FSWs

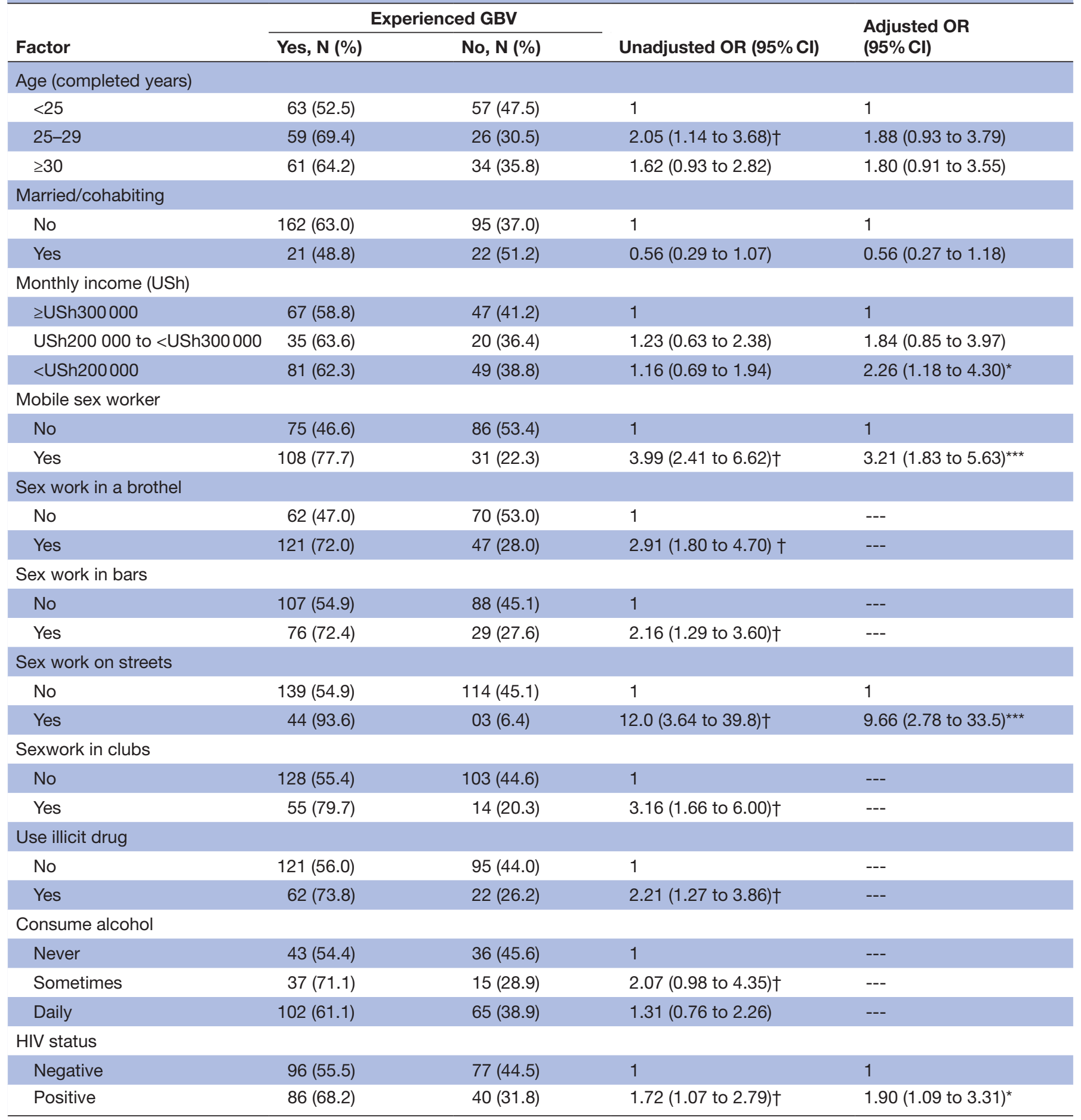

${ }^{*} \mathrm{P}<0.05,{ }^{* * *} \mathrm{p}<0.001$.

†Significant at $p<0.20$ and entered into the multivariable model.

FSW, female sex worker; GBV, gender-based violence.

\section{Strengths and limitations of the study}

Unlike most previous studies among FSWs that used nonprobability sampling methods, we used a simple random sampling technique to select our sample. Thus, the study participants were representative of FSWs in the area and more generalisable for FSWs in similar settings. This study had some limitations: data collected may have been negatively influenced by recall bias since we asked FSWs about their personal experience of client-perpetrated GBV. Besides, we implored some sensitive information relating to sex work that might have been difficult to answer and thus under-reported. However, we interviewed FSWs in such a way that we reduce any chance of information bias. 


\section{CONCLUSION}

There is a high prevalence of client-perpetrated GBV among FSWs in conflict-affected Northern Uganda. Further analysis indicated that street-based, mobile, lowincome earning and HIV-positive FSWs were more likely to experience client-perpetrated GBV. Therefore, the ministry of health and the development partners need to provide targeted public health interventions that prevent and manage GBV among this underserved population.

\section{Twitter Rawlance Ndejjo @Rawleng}

Acknowledgements We acknowledge; Professor Christopher Garimoi Orach, Professor Fred Nuwaha and Assoc. Professor Noah Kiwanuka for their insightful contributions to our study designs. Likewise, we thank TASO Gulu for allowing us to access their up-to-date database of FSWs who operated in Gulu. We acknowledge Ms Ajwang Brenda for her role as a research assistant for this study. Last but not least, we appreciated the contributions of all study participants and peers of FSWs that enabled the smooth conduct of this study.

Contributors SO conceived and designed the study, collected and entered data, conducted data analysis, interpreted the findings and wrote the first draft of the manuscript. RN, CA and NMT conceived the study, supported data analysis and critically reviewed the draft manuscript. All authors approved the final manuscript for publication.

Funding The authors have not declared a specific grant for this research from any funding agency in the public, commercial or not-for-profit sectors.

Competing interests None declared.

Patient and public involvement Patients and/or the public were involved in the design, or conduct, or reporting, or dissemination plans of this research. Refer to the Methods section for further details.

\section{Patient consent for publication Not required.}

Ethics approval We obtained ethical clearance for this study from Makerere University School of Public Health Higher Degrees, Research and Ethics Committee (No: 2017/HD07/2063U). Each participant provided written informed consent. We maintained participants' privacy and confidentiality throughout the different processes of participant enrolment, data collection, analysis and reporting.

Provenance and peer review Not commissioned; externally peer reviewed.

Data availability statement Data are available on reasonable request. The datasets used and analysed during the current study are available from the corresponding author on reasonable request.

Open access This is an open access article distributed in accordance with the Creative Commons Attribution Non Commercial (CC BY-NC 4.0) license, which permits others to distribute, remix, adapt, build upon this work non-commercially, and license their derivative works on different terms, provided the original work is properly cited, appropriate credit is given, any changes made indicated, and the use is non-commercial. See: http://creativecommons.org/licenses/by-nc/4.0/.

\section{ORCID iDs}

Simple Ouma http://orcid.org/0000-0002-4510-6736

Rawlance Ndejjo http://orcid.org/0000-0001-9263-557X

\section{REFERENCES}

1 UNHCR. Gender-based violence. Available: https://www.unhcr.org/ gender-based-violence.html [Accessed 12 Mar 2021]

2 Brown G, Langer A, Stewart F. A typology of Post-Conflict environments. Centre for Research on Peace and Development (CRDP), 2011.

3 Patel S, Schechter MT, Sewankambo NK, et al. War and HIV: sex and gender differences in risk behaviour among young men and women in post-conflict Gulu district, Northern Uganda. Glob Public Health 2014;9:325-41.

4 Black E, Worth $\mathrm{H}$, Clarke S, et al. Prevalence and correlates of intimate partner violence against women in conflict affected Northern Uganda: a cross-sectional study. Confl Health 2019;13:1-10.

5 Mugisha J, Muyinda H, Malamba S, et al. Major depressive disorder seven years after the conflict in northern Uganda: burden, risk factors and impact on outcomes (the Wayo-Nero study). BMC Psychiatry 2015;15:1-12.

6 United Nations General Assembly. Declaration on the elimination of violence against women (A/48/629), 1994: 1-7.

7 Jiwatram-Negrón T, El-Bassel N, Primbetova S, et al. Gender-Based violence among HIV-positive women in Kazakhstan: prevalence, types, and associated risk and protective factors. Violence Against Women 2018;24:1570-90.

8 Ouma S, Tumwesigye NM, Ndejjo R, et al. Prevalence and factors associated with major depression among female sex workers in post-conflict Gulu district: a cross-sectional study. BMC Public Health 2021;21:1-10.

9 Deering KN, Amin A, Shoveller J, et al. A systematic review of the correlates of violence against sex workers. Am J Public Health 2014;104:e42-54.

10 Erickson M, Goldenberg SM, Master A, et al. Interpersonal and structural contexts of intimate partner violence among female sex workers in conflict-affected Northern Uganda. Women Health 2018;58:759-73.

11 Ramesh S, Ganju D, Mahapatra B, et al. Relationship between mobility, violence and HIV/STI among female sex workers in Andhra Pradesh, India. BMC Public Health 2012;12:764.

12 Hendrickson ZM, Leddy AM, Galai N, et al. Work-Related mobility and experiences of gender-based violence among female sex workers in Iringa, Tanzania: a cross-sectional analysis of baseline data from project Shikamana. BMJ Open 2018;8:e022621-11.

13 Ateenyi F, Linnete D. Legal regulation of sex work in Uganda : exploring the current trends and their impact on the human rights of sex workers. Kampala, 2016.

14 Scorgie F, Nakato D, Harper E, et al. 'We are despised in the hospitals': sex workers' experiences of accessing health care in four African countries. Cult Health Sex 2013;15:450-65.

15 Decker MR, Lyons C, Billong SC, et al. Gender-Based violence against female sex workers in Cameroon: prevalence and associations with sexual HIV risk and access to health services and justice. Sex Transm Infect 2016;92:599-604.

16 Schulkind J, Mbonye M, Watts C, et al. The social context of genderbased violence, alcohol use and HIV risk among women involved in high-risk sexual behaviour and their intimate partners in Kampala, Uganda. Cult Health Sex 2016;18:770-84.

17 Li Q, Li X, Stanton B. Alcohol use among female sex workers and male clients: an integrative review of global literature. Alcohol Alcohol 2010;45:188-99.

18 Beattie TS, Bhattacharjee P, Isac S, et al. Declines in violence and police arrest among female sex workers in Karnataka state, South India, following a comprehensive HIV prevention programme. J Int AIDS Soc 2015;18:20079-16.

19 Sherwood JA, Grosso A, Decker MR, et al. Sexual violence against female sex workers in the Gambia: a cross-sectional examination of the associations between victimization and reproductive, sexual and mental health. BMC Public Health 2015;15:1-10.

20 Patel SK, Ganju D, Prabhakar P, et al. Relationship between mobility, violence and major depression among female sex workers: a cross-sectional study in southern India. BMJ Open 2016;6:e011439.

21 Prince M, Patel V, Saxena S, et al. No health without mental health. Lancet 2007;370:859-77.

22 Sagtani RA, Bhattarai S, Adhikari BR, et al. Violence, HIV risk behaviour and depression among female sex workers of eastern Nepal. BMJ Open 2013;3:e002763-6.

23 Ulibarri MD, Hiller SP, Lozada R, et al. Prevalence and characteristics of abuse experiences and depression symptoms among injection drug-using female sex workers in Mexico. J Environ Public Health 2013;2013:1-11.

24 Ministry of Health. Consolidated guidelines for prevention and treatment of HIV in Uganda, 2016.

25 Uganda Bureau of Statistics. National population and housing census 2014: area specific profiles Gulu district. Kampala, 2017.

26 Apodaca K, Doshi RH, Ogwal M, et al. Capture-Recapture among men who have sex with men and among female sex workers in 11 towns in Uganda. JMIR Public Health Surveill 2019;5:e12316.

27 PEPFAR. Improving access to HIV treatment services through community art distribution points in Uganda, 2006.

28 Isreal GD. Determining sample size. Vol. PEOD6, determining sample size, 1992: 1-5.

29 Schwitters A, Swaminathan M, Serwadda D, et al. Prevalence of rape and Client-Initiated gender-based violence among female sex workers: Kampala, Uganda, 2012. AIDS Behav 2015;19:68-76.

30 Costanza MC, Afifi AA. Comparison of stopping rules in forward stepwise discriminant analysis. J Am Stat Assoc 1979;74:777-85. 
31 Phorano O, Nthomang K, Ntseane D. Alcohol abuse, gender-based violence and HIV/AIDS in Botswana: establishing the link based on empirical evidence. Sahara J 2005;2:188-202.

32 African Sex Worker Alliance. "Every sex worker has got a story to tell about violence" : Violence against sex workers in Africa. Nairobi, 2019.

33 Semple SJ, Stockman JK, Pitpitan EV, et al. Prevalence and correlates of client-perpetrated violence against female sex workers in 13 Mexican cities. PLoS One 2015;10:e0143317.

34 Shannon K, Strathdee SA, Shoveller J, et al. Structural and environmental barriers to condom use negotiation with clients among female sex workers: implications for HIV-prevention strategies and policy. Am J Public Health 2009;99:659-65.

35 World Health Organization. Violence against women and HIVI AIDS: critical Intersections - violence against sex workers and HIV prevention, 2005

36 Goldenberg SM, Chettiar J, Nguyen P, et al. Complexities of shortterm mobility for sex work and migration among sex workers: violence and sexual risks, barriers to care, and enhanced social and economic opportunities. J Urban Health 2014;91:736-51.
37 Maman S, Mbwambo JK, Hogan NM, et al. Hiv-Positive women report more lifetime partner violence: findings from a voluntary counseling and testing clinic in Dar ES Salaam, Tanzania. Am J Public Health 2002:92:1331-7.

38 El-Bassel N, Witte SS, Wada T, et al. Correlates of partner violence among female street-based sex workers: substance abuse, history of childhood abuse, and HIV risks. AIDS Patient Care STDS 2001;15:41-51.

39 Decker MR, Yam EA, Wirtz AL, et al. Induced abortion, contraceptive use, and dual protection among female sex workers in Moscow, Russia. Int J Gynaecol Obstet 2013;120:27-31.

40 Zhang $\mathrm{C}$, Li X, Hong Y, et al. Partner violence and HIV risk among female sex workers in China. AIDS Behav 2012;16:1020-30.

41 Hladik W, Baughman AL, Serwadda D, et al. Burden and characteristics of HIV infection among female sex workers in Kampala, Uganda - a respondent-driven sampling survey. BMC Public Health 2017;17:1-12.

42 Alemayehu M, Yohannes G, Damte A, et al. Prevalence and predictors of sexual violence among commercial sex workers in northern Ethiopia. Reprod Health 2015;12:47. 